\title{
Impedance-type measurements using XPS
}

\author{
Sefik Suzer ${ }^{a, *}$, Esta Abelev ${ }^{b}$, Steven L. Bernasek ${ }^{b}$ \\ a Department of Chemistry, Bilkent University, 06800 Ankara, Turkey \\ ${ }^{\mathrm{b}}$ Department of Chemistry, Princeton University, Princeton, NJ 08544-1009, United States
}

\section{A R T I C L E I N F O}

Article history:

Available online 20 October 2009

\section{Keywords:}

XPS

Charging

Impedance

Bilayer OTS

$\mathrm{Rb}$-atom

\begin{abstract}
A B S T R A C T
An impedance type of measurement using X-ray photoelectron spectroscopy is applied for probing charging/discharging dynamics of a sample containing $\mathrm{Rb}$ deposited on a $\mathrm{SiO}_{2} / \mathrm{Si}$ substrate containing an octadecyltrichlorosilane (OTS) bilayer coating. The OTS bilayer coatings have possible use as antirelaxation wall coatings for alkali atom vapor cells in miniaturized instruments such as chip-scale atomic clocks, and/or magnetometers. The measurement consists of the application of bipolar square wave pulses of $\pm 10.0 \mathrm{~V}$ amplitude to the sample with varying frequencies in the range of $10^{-2}$ to $10^{2} \mathrm{~Hz}$ while recording X-ray photoemission data. For a conducting sample this type of measurement twins all the photoemission peaks at -10.0 and $+10.0 \mathrm{eV}$ positions at all frequencies with exactly $20.0 \mathrm{eV}$ difference between them. However, for samples amenable to charging, the difference between the twinned peaks is less than $20.0 \mathrm{eV}$, and gradually decreases at correspondingly lower frequencies. For the sample under consideration here at $0.01 \mathrm{~Hz}$, the twinned $01 \mathrm{~s}$ and $\mathrm{Si} 2 \mathrm{p}$ peaks, representing the $\mathrm{SiO}_{2}$ substrate, are separated by $18.2 \mathrm{eV}$, displaying a $1.8 \mathrm{eV}$ charging shift. These positions differ from those of the $\mathrm{C} 1 \mathrm{~s}(18.0 \mathrm{eV})$ representing the OTS bilayer and the Rb3d peaks $(18.1 \mathrm{eV})$. These results reveal that the $\mathrm{Rb}$ is electrically (perhaps also chemically) isolated from the OTS bilayer, which may be correlated with the improved performance of the OTS bilayers as anti-relaxation coatings in these alkali atom magnetometer cells.
\end{abstract}

(c) 2009 Elsevier B.V. All rights reserved.
Accumulation and dissipation of charges (charging/discharging) in dielectric materials are vital processes for design and function of various devices and sensors [1]. Charge accumulation in a dielectric layer occurs via various trapping mechanism(s) and is normally probed by electrical current-voltage and/or currentcapacitance measurements [2-5]. Photoemission, utilizing UV, Xrays and lasers has also been employed for probing very fast $\left(<10^{-9} \mathrm{~s}\right)$ charging dynamics [6-8]. Core-level X-ray photoemission, XPS, is especially attractive since additional chemical information can also be derived from the line positions of the corresponding peaks. However, the measured line positions are severely affected by local potentials developed due to the uncompensated charges resulting from photoelectron emission, especially for nonconducting samples or regions (layers or domains) within such samples [9-15]. Over the last 3-4 decades, very successful methods of charge compensation in photoelectron spectroscopy have been developed using low energy electrons, ions and/or photons [16,17].

One can also use XPS for understanding the mechanisms leading to and/or controlling the charging/discharging processes in materials, which offer great possibilities for researchers in all fields [18]. Several successful applications have already been reported,

\footnotetext{
* Corresponding author. Tel.: +90 312 2901476/2664946; fax: +90 3122664068 . E-mail address: suzer@fen.bilkent.edu.tr (S. Suzer).
}

which utilize the charging for extracting chemical, physical, structural, and electrical parameters of various surface species [19-25]. Using a slightly different strategy and by applying voltage stress to the sample while recording XPS spectra, we have shown that the extent of charging can be controlled, as a result of which a range of analytical and electrical information can be extracted [2631]. In addition to static information derived from application of d.c. voltage stress, dynamical information can also be extracted by application of the voltage stimuli in the form of square wave pulses, as we have recently reported [29,32-35]. In our previous measurements we used an unmonochromatized X-ray source where, in addition to characteristic $\mathrm{Mg} \mathrm{K} \alpha$ radiation, it also emits wide bremstrahlung radiation and low energy electrons, which are known to affect charging of the samples under investigation. In this contribution we extend our investigation to analysis of XPS data using a monochromated $\mathrm{Al} \mathrm{K \alpha}$ source and apply the voltage stress in the form of bipolar square wave pulses for following charging/ discharging dynamics of thin dielectric surface structures in order to extract analytical information. We have chosen a composite sample containing $\mathrm{Rb}$ atoms deposited on an octadecyltrichlorosilane (OTS) bilayer attached to a $\mathrm{SiO}_{2} / \mathrm{Si}$ substrate. These OTS bilayer coatings show some promise as anti-relaxation coatings for the interior surfaces of alkali atom vapor cells used in atomic magnetometry [36].

The bilayer OTS films were grown on $\mathrm{SiO}_{2}(100 \mathrm{~nm}) / \mathrm{Si}$ substrates by use of a procedure that has been previously 
described [37]. The substrate with the OTS bilayers was sealed into an evacuated glass bulb along with $\mathrm{Rb}$ metal. The entire bulb was heated to $120^{\circ} \mathrm{C}$ for $24 \mathrm{~h}$ to expose the OTS coatings to Rb vapor, as done in actual atomic resonance cells. After the $24 \mathrm{~h}$ period of $\mathrm{Rb}$ exposure, the glass bulb was kept at $120^{\circ} \mathrm{C}$, except for a small spot that was cooled to room temperature. This cold spot was used to trap excess, unreacted $\mathrm{Rb}$ atoms that evaporate from the warm OTS surfaces. $\mathrm{Rb}$ atoms were trapped for a period of $12 \mathrm{~h}$. Once cooled to room temperature, the glass bulb was opened in a glove box, and the substrates were removed for XPS studies. XP spectra of the OTS coatings were collected using a SPECS Phoibos 150 hemispherical energy analyzer with a monochromated $\mathrm{Al} \mathrm{K \alpha}$ source. A pass energy of $10 \mathrm{eV}$ was used for the XPS scans of the Si2p, Rb3d, O1s, and $\mathrm{C} 1 \mathrm{~s}$ regions. A filament placed near the sample provided low energy electrons for neutralization. The sample was electrically connected to the sample holder, which is grounded or pulsed by a square wave in the range of $10^{-2}$ to $10^{2} \mathrm{~Hz}$ while recording the XP spectra.

In Fig. 1(a) we display the 01s region of the XPS spectra of the sample recorded when the sample is grounded (olive), under $-10 \mathrm{~V}$ (blue) and $+10 \mathrm{~V}$ (red) d.c. voltage stress. The 01s peak consists mainly of the dielectric $\mathrm{SiO}_{2}$ layer and exhibits charging shifts under application of the voltage bias with different polarities. For example, under $-10 \mathrm{~V}$ bias, the peak is shifted to an apparently lower binding energy (higher kinetic energy, blue shift), and since there is not much of a difference between the low energy electron current flowing from the sample with respect to the grounded sample, the shift is exactly $-10.0 \mathrm{eV}$. However, in the case of the positive bias, low energy electrons from the nearby filament are attracted to the sample causing a proportionally larger current to yield a shift of only $+8.2 \mathrm{eV}$ towards the higher binding energy side (red shift), resulting in a $-1.8 \mathrm{eV}$ charging shift.

In Fig. 1(b) the same O1s region is displayed when the sample is subjected to bipolar square wave pulses of $\pm 10 \mathrm{~V}$ amplitude at 5 different frequencies, which is equivalent to applying $+10 \mathrm{~V}$ and $-10 \mathrm{~V}$ in an alternating sequence. At high frequencies the sample does not have enough time to charge nor discharge resulting in twinned peaks of $20.0 \mathrm{eV}$ separation, but as the frequency is lowered the positive peak starts to exhibit larger charging shifts approaching that of the negative d.c. bias. These frequency dependent XPS shifts are measurements that probe the impedance of the sample under consideration, and can yield additional information which can be related to the resistancecapacitance of the composite sample [32-35].

In Fig. 2, we display $\mathrm{C} 1 \mathrm{~s}, \mathrm{Si} 2 \mathrm{p}$ and $\mathrm{Rb} 3 \mathrm{~d}$ peaks recorded at $0.01 \mathrm{~Hz}$, where each peak exhibits a slightly different shift due the

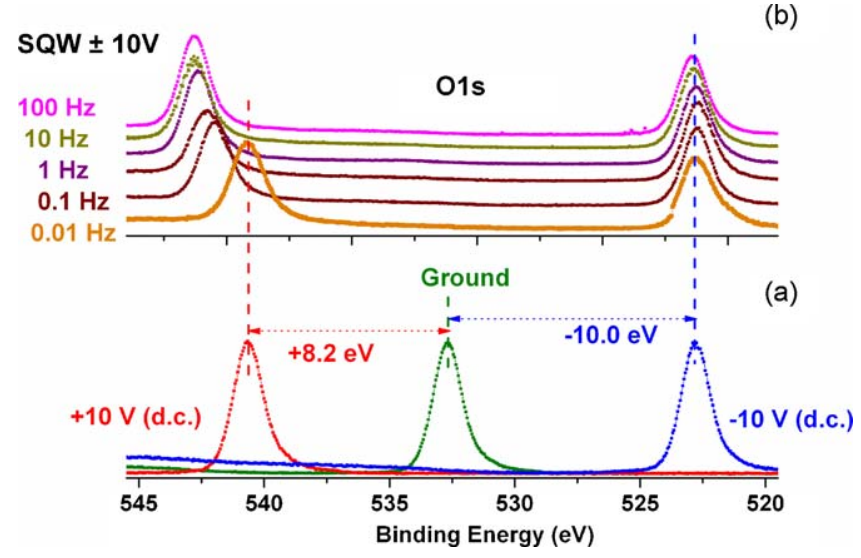

Fig. 1. (a) XPS spectrum of the 01s region recorded when the sample is grounded (olive), and when subjected to $+10.0 \mathrm{~V}$ (red) and $-10 \mathrm{~V}$ (blue) voltage bias. (b) The same $01 \mathrm{~s}$ region under $\pm 10 \mathrm{~V}$ bipolar square pulses with varying frequencies. (For interpretation of the references to color in this figure legend, the reader is referred to the web version of the article.)

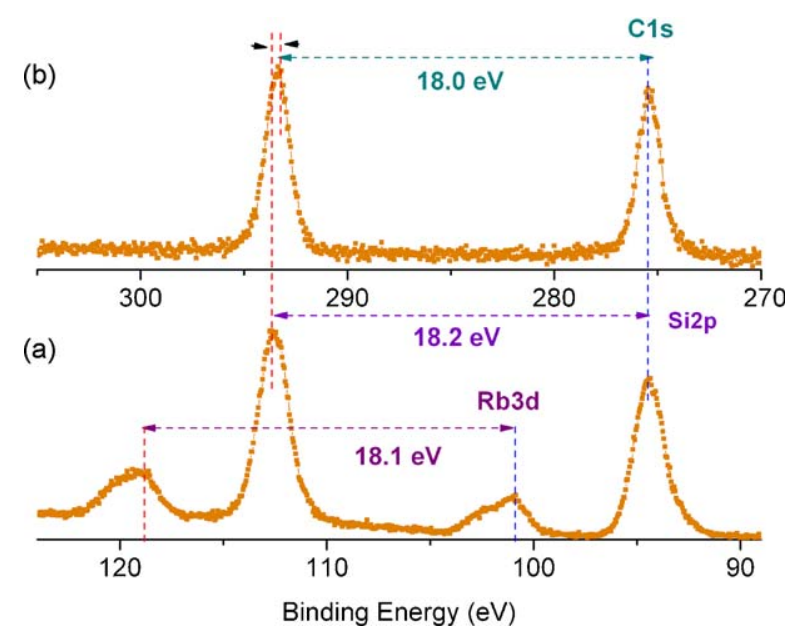

Fig. 2. XPS spectrum of the sample recorded at $0.01 \mathrm{~Hz}$; (a) the Si2p and the Rb3d, and (b) the $\mathrm{C} 1 \mathrm{~s}$ region.

different extent of charging they experience. This is similar to our previous observations with other composite samples [33-35]. Whereas, the Si2p peak separation is exactly the same as that of O1s $(18.2 \mathrm{eV})$, the Rb3d and C1s peaks are separated by 18.1 and $18.0 \mathrm{eV}$, respectively, revealing that to some extent, the $\mathrm{Rb}$ and $\mathrm{C}$ moieties are electrically isolated (and chemically distinct) from each other. This is also consistent with the measured binding energy of the Rb3d level of $110.5 \mathrm{eV}$, which is in between that of the metal $(112.0 \mathrm{eV})$ and the ionic $\mathrm{Rb}^{+}(110.1 \mathrm{eV})$, most probably corresponding to a small cluster of $\mathrm{Rb}^{0}$ system [15]. Moreover, this finding is also in accord with the comprehensive work of Czanderna and co-workers, where although no mention of $\mathrm{Rb}$ is explicitly given, $\mathrm{Na}$ and $\mathrm{K}$ are listed among the metal atoms which are found to be not significantly reacting with the various organic SAMs [36].

Scheme 1 summarizes the shifts of each peak and gives a schematic representation of the charges accumulated at different regions of the composite sample under consideration. Note that only through these impedance type of measurements can the difference between the $\mathrm{Rb}$ and $\mathrm{C}$ moieties be detected. This difference may be correlated with the better alkali atom antirelaxation performance of the cells coated with OTS bilayers [3739].

These dynamical measurements pave the way to a number of analytical tools for extracting information about charging/ discharging of surface structures. In this simple application we have been able to identify the electrical difference between the OTS

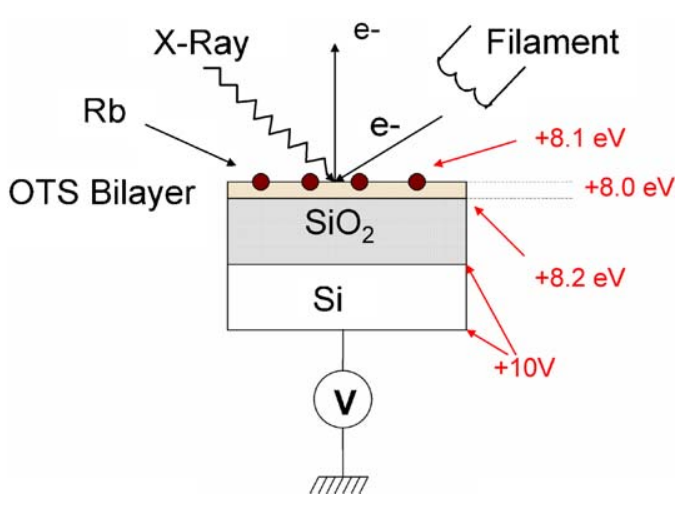

Scheme 1. The schematics of the experimental set up and the measured potentials at different regions under the $+10 \mathrm{~V}$ cycle of the $0.01 \mathrm{~Hz}$ bipolar square wave applied. 
bilayer and the $\mathrm{Rb}$ moieties. This technique turns XPS into a powerful and non-contact impedance spectrometer with the added advantage of chemical resolution and specificity.

\section{Acknowledgement}

This work was partially supported by TUBA (Turkish Academy of Sciences) and by TUBITAK (The Scientific and Technological Research Council of Turkey) through the Grant No: $106 T 409$. Partial support of the U.S. National Science Foundation, Division of Chemistry, CHE-0616457 is gratefully acknowledged.

\section{References}

[1] S.M. Sze, Physics of Semiconductor Devices, Wiley, New York, 1981.

[2] O.L. Curtis Jr., J.R. Srour, J. Appl. Phys. 48 (1977) 3819.

[3] R.C. Hughes, Phys. Rev. B 15 (1977) 2012.

[4] T. Wang, T.E. Cheng, L.P. Chiang, C.H. Wang, N.K. Zons, C. Huang, IEEE Trans. Electron. Devices 45 (1998) 1511.

[5] C.J. Kang, G.H. Buh, S. Lee, C.K. Kim, K.M. Mang, C. Im, Y. Kuk, Appl. Phys. Lett. 74 (1999) 1815.

[6] H. Hovel, B. Grimm, M. Pollmann, B. Reihl, Phys. Rev. Lett. 81 (1998) 4608.

[7] M. Marsi, R. Belkhou, C. Grupp, G. Panaccionne, A. Taleb-Ibrahimi, L. Nahon, D. Garzella, D. Nutarelli, E. Renault, R. Roux, M.E. Couprie, M. Billardon, Phys. Rev. B 61 (2000) R5070.

[8] M. Bauer, C. Lei, K. Read, R. Tobey, J. Gland, M.M. Murnane, H.C. Kapteyn, Phys. Rev. Lett. 87 (2001) 025501.

[9] J.P. Countour, G. Mouvier, Chem. Phys. Lett. 33 (1975) 237.

[10] T.L. Barr, Crit. Rev. Anal. Chem. 22 (1991) 229.

[11] W.M. Lau, J. Appl. Phys. 65 (1989) 2047.
[12] A. Fernandez, J.P. Espinos, D. Leinen, A.R. Gonzales-Elipe, J.M. Sanz, Surf. Interface Anal. 22 (1994) 111

[13] B.J. Tielsch, J.E. Fulghum, Surf. Interface Anal. 25 (1997) 904

[14] N.J. Havercroft, P.M.A. Sherwood, Surf. Interface Anal. 29 (2000) 232.

[15] D. Briggs, M.P. Seah, Practical Surface Analysis. Part I. Auger and X-ray Photoelectron Spectroscopy, 2nd ed., John Wiley \& Sons Ltd., England, 1996.

[16] J. Cazaux, J. Electron Spectrosc. Relat. Phenom. 105 (1999) 155.

[17] J. Cazaux, J. Electron Spectrosc. Relat. Phenom. 113 (2000) 15.

[18] M. Grimm, B. langer, S. Schlemmer, T. Lischke, U. Becker, W. Widdra, D. Gerlich, R Flesch, E. Ruhl, Phys. Rev. Lett. 96 (2006) 066801.

[19] W.M. Lau, X.W. Wu, Surf. Sci. 245 (1991) 345.

[20] S. Iwata, A. Ishizaka, J. Appl. Phys. 79 (1996) 6653.

[21] H. Doron-Mor, A. Hatzor, A. Vaskevich, T. van der Boom-Moav, A. Shanzer, I. Rubinstein, H. Cohen, Nature 406 (2000) 382.

[22] K. Shabtai, I. Rubinstein, S.R. Cohen, H. Cohen, J. Am. Chem. Soc. 122 (2000) 4959

[23] H. Cohen, Appl. Phys. Lett. 85 (2004) 1271.

[24] M. Dubey, I. Gouzman, S.L. Bernasek, J. Schwartz, Langmuir 22 (2006) 4649.

[25] I. Gouzman, M. Dubey, M.D. Carolus, J. Schwartz, S.L. Bernasek, Surf. Sci. 600 (2006) 773.

[26] S. Suzer, Anal. Chem. 75 (2003) 7026

[27] F. Karadas, G. Ertas, S. Suzer, J. Phys. Chem. B 108 (2004) 1515.

[28] G. Ertas, S. Suzer, Surf. Interface Anal. 36 (2004) 619.

[29] U.K. Demirok, G. Ertas, S. Suzer, J. Phys. Chem. B 108 (2004) 5179.

[30] G. Ertas, U.K. Demirok, S. Suzer, Appl. Surf. Sci. 249 (2005) 12.

[31] G. Ertas, U.K. Demirok, A. Atalar, S. Suzer, Appl. Phys. Lett. 86 (2005) 183110

[32] E. Karabudak, U.K. Demirok, S. Suzer, Surf. Sci. Lett. 600 (2006) 12.

[33] S. Suzer, A. Dana, J. Phys. Chem. B 110 (2006) 19112.

[34] H. Sezen, G. Ertas, A. Dana, S. Suzer, Macromolecules 40 (2007) 4109.

[35] T.O. Tasci, E. Atalar, U.K. Demirok, S. Suzer, Surf. Sci. 602 (2008) 365.

[36] D.R. Jung, A.W. Czanderna, G.C. Herdt, J. Vasc. Sci. Technol. A 14 (1996) 1779.

[37] Y.W. Yi, H.G. Robinson, H. Knappe, et al. Appl. Phys. Lett. 104 (2008) 023534.

[38] J. Seltzer, D.M. Rampulla, S. Rivillon-Amy, Y.J. Chabal, S.L. Bernasek, M.V. Romalis, J. Appl. Phys. 104 (2008) 103116

[39] D.M. Rampulla, N. Oncel, E. Abelev, Y.W. Yi, S. Knappe, S.K. Bernasek, Appl. Phys. Lett. 94 (2009) 041116. 